\title{
El pago único de la prestación por desempleo como medio de financiación inicial de las empresas de Economía Social en España
}

\section{Juan José Plaza-Angulo y Antonio Manuel Ciruela Lorenzo}

RESUMEN: El Real Decreto 1044/85, de 19 de junio, configura la prestación por desempleo mediante pago único como un instrumento para el fomento del empleo. Desde entonces ha sido la base sobre la que se han desarrollado numerosas iniciativas empresariales dentro y fuera de la Economía Social.

La trascendencia de esta modalidad de prestación para la Economía Social radica, además de en la reducción de la dificultad de financiación, quizás común en todas las figuras empresariales, en el hecho de que estas organizaciones pueden generar mayores efectos en el empleo que el resto. Es por ello por lo que se va a analizar la repercusión de dicha prestación en las empresas de economía social, más concretamente en las sociedades laborales y cooperativas por ser las que ostentan un mayor grado de representatividad en este sector.

Este trabajo aborda el marco jurídico de la prestación por desempleo. Se lleva a cabo una revisión de la literatura, destacando los principales autores que han trabajado sobre dicha temática, y se analizan los datos disponibles del Ministerio de Empleo y Seguridad Social. Concluye con el desarrollo de un estudio empírico que complementa y contrasta la información disponible y, además, concreta ciertas cuestiones sobre las que aún no se disponía de información.

PALABRAS CLAVE: Empresas de Economía Social, pago único por capitalización de desempleo, financiación, emprendedores.

CLAVES ECONLIT: G28, L31, P13.

Cómo citar este artículo / How to cite this article: PLAZA-ANGULO, J.J. \& CIRUELA-LORENZO, A.M. (2017):

"El pago único de la prestación por desempleo como medio de financiación inicial de las empresas de Economía

Social en España", CIRIEC-España, Revista de Economía Pública, Social y Cooperativa, 91, 85-113.

Correspondencia: Juan José Plaza-Angulo, Universidad de Málaga, Profesor asociado, Doctor, e-mail:

juanjoseplaza@uma.es; Antonio Manuel Ciruela Lorenzo, Universidad de Málaga, Profesor Contratado Doctor, e-mail: acl@uma.es. 


\section{EXPANDED ABSTRACT}

\section{Single unemployment benefit payment as a means of initial financing for Social Economy enterprises in Spain}

\section{Objective}

The single unemployment benefit payment is a method that has been used to foster self-employment since 1985, when it was ratified under Spanish Royal Decree 1044/85, dated 19th June. The aim of this measure is to foster and facilitate self-employment initiatives, and consists of payment of the current value of the contributory unemployment benefit to claimants who intend to set up a cooperative or employee-owned company, join an existing company as a self-employed partner or carry out a new activity as a self-employed worker.

Since coming into effect, it has formed the basis of numerous professional and business initiatives (Martín et al., 2005) both in the wider context and in the social economy sector. Its significance lies in the difficulties encountered when seeking finance for business in general, and in particular for social economy enterprises (Coll and Cuñat, 2006;Plaza-Angulo,2011; Álamo et al. 2015), and in the fact that investment in this type of undertaking may generate effects in employment that are considerably higher than the global average (Fuentes and Mainar, 2015).

Based on these studies it seems that the single unemployment payment is the benefit that makes a general contribution to the initial financing of cooperatives and employee-owned companies, and is instrumental in the creation of stable employment. To support the hypothesis, this paper describes the legal framework of the benefit, reviews the literature on the subject and analyses Ministry of Employment and Social Security (MESS) data, before elaborating on an original questionnaire formulated to generate supplementary data and provide a contrast with official information.

\section{Design/methodology/approach}

In order to appreciate the nature and characteristics of the benefit, this paper begins with an analysis of the legal context, which is followed by an explanation of the theoretical framework and an analysis of the main official MESS statistics. Additionally, to paint a clearer picture of the subject and corroborate certain of the research hypotheses, we conducted a quantitative analysis based on a telephone survey. 


\section{EL PAGO ÚNICO DE LA PRESTACIÓN POR DESEMPLEO COMO MEDIO DE FINANCIACIÓN INICIAL DE LAS EMPRESAS DE ECONOMÍA SOCIAL EN ESPAÑA}

The population under study is employee-owned companies and cooperatives in Spain, excluding housing or consumer cooperatives and second or higher degree cooperatives. The reference group was composed of 10,313 employee-owned companies and 11,956 cooperatives, i.e. 22,269 social economy businesses located in Spain in 2015.

Sampling is stratified and proportional to the number of businesses that constitute the study population. Thus, the sample consisted of a total 378 businesses, of which 176 are employee-owned companies and 202 are cooperatives. The chosen method for selection of the businesses that would participate in the survey was simple random sampling.

\section{Findings}

The number of unemployment beneficiaries who decide to capitalise their benefit in order to set up or join a new or existing social economy business is only $4.36 \%$. Within this group of entrepreneurs, $77.6 \%$ of our interviewees stated that access to the single payment was a decisive factor when setting up their business venture or joining an existing business.

This type of venture rarely resorts to external financing. In fact, in $63.4 \%$ of cases the partners contributed more than $76 \%$ of the equity or share capital for the business from personal savings. On the other hand, $46.4 \%$ of the partners opted to capitalise their unemployment benefit to finance their contribution to company equity while in only $2.5 \%$ of the companies none of the partners opted for this benefit. Each partner who capitalised his or her unemployment benefit did so to an average value of $4,108.2$ euros and, moreover, $79.4 \%$ of the businesses reported that they had no access to any other funding or subsidy.

It is estimated that the total average amount to which partners have a right is 12,200.1 euros, of which 4,108.2 euros (33.67\%) is used to cover the amount devoted to equity/share capital and other expenses necessary to become a partner, and an average 8,091.9 euros (66.33\%) defrays the costs of monthly Social Security contributions (not attributable to the company). That is to say, the business venture itself only benefits from $33.67 \%$ of the amount to which the worker really has a right. This amount is small when considering the initial financial needs of any business venture, however, for $79.4 \%$ of businesses this is the only funding or subsidy they have had access to.

\section{Research limitations/implications}

The lack of previous empirical research quantifying the impact of the benefit, along with the generality of official MESS data, has limited the information that can be contributed, although this is precisely the reason that justified our paper and its empirical study. 
Due to the lack of funding available to conduct this study, it has not been possible to go into any greater depth, and other collectives that also have the right to this benefit, such as self-employed workers, have been excluded. In the future, it may be pertinent to study this group, or even to segment data by autonomous community, which would help understand the impact of salary on the amount of the benefit and, ultimately, on the financing of a business venture.

\section{Practical conclusions}

In light of the results of this study, we can assert that the single payment constitutes the main benefit to which this type of entrepreneur can resort. Despite its small economic value, the benefit is clearly vital for this type of business, which rarely resorts to external financing and covers its needs with personal contributions. This endorses aspects previously highlighted in works such as those of Coll and Cuñat (2006), Lejarriaga et al. (2010), Plaza-Angulo (2011), Lejarriaga et al. (2013), Plaza-Angulo and Rico (2013), Álamo et al. (2015) or Sanchis et al. (2015), upon which we have based our hypothesis.

For all of these reasons, it can be stated that the single unemployment benefit payment is the benefit that makes a general contribution to the initial financing of cooperatives and employee-owned companies, thus fostering the creation of stable employment.

\section{Originality/value}

This is one of the first pieces of empirical research that contributes its own data on the subject and highlights the importance of the single payment for social economy entrepreneurs. It likewise facilitates extension of the reseach to the other collectives concerned, and lays the foundations for a much needed debate on future reforms to improve this benefit in terms of its amount, among the beneficiary population, and regarding its equality countrywide.

KEYWORDS: Social economy, single unemployment benefit payment, financing, entrepreneurs. 


\section{EL PAGO ÚNICO DE LA PRESTACIÓN POR DESEMPLEO COMO MEDIO DE FINANCIACIÓN INICIAL DE LAS EMPRESAS DE ECONOMÍA SOCIAL EN ESPAÑA}

\section{Introducción*}

Desde que en 1985, mediante Real Decreto 1044/85 de 19 de junio, se configura la prestación por desempleo mediante pago único como instrumento para el fomento del empleo, ésta ha sido la base sobre la que se han desarrollado numerosas iniciativas profesionales y empresariales (Martín, et al., 2005) dentro y fuera de la Economía Social. En este trabajo vamos a analizar la repercusión de dicha prestación en las empresas de economía social, más concretamente en las sociedades laborales y cooperativas, por ser las que ostentan una mayor representatividad en dicho sector.

El pago único es una herramienta utilizada en el abono de la prestación por desempleo como medida de fomento del autoempleo. En palabras de Álvarez y Plaza-Angulo (2008) se trata de una medida para fomentar y facilitar iniciativas de autoempleo, a través del abono del valor actual del importe de la prestación por desempleo de nivel contributivo a los beneficiarios de prestaciones que pretenden incorporarse, de forma estable, como socios trabajadores o de trabajo en cooperativas 0 en sociedades laborales, constituirlas, o que quieren desarrollar una nueva actividad como trabajadores autónomos. El abono de la prestación se realizará de una sola vez por el importe que corresponda a la aportación obligatoria establecida con carácter general en cada cooperativa 0 al de la adquisición de acciones o participaciones del capital social en una sociedad laboral. También puede utilizarse, en su totalidad o en la parte sobrante tras cubrir dichas aportaciones obligatorias, para subvencionar las cuotas a la Seguridad Social que corresponden al trabajador.

En España, según datos del Ministerio de Trabajo y Seguridad Social para 2015, existen 22.269 empresas de economía social, que dan trabajo directo a 284.843 trabajadores. Además, en dicho año se constituyeron un total de 1.865 nuevas empresas integradas por 10.450 socios-trabajadores. Son estos socios-trabajadores los que, si cumplen con los requisitos necesarios para obtener una prestación por desempleo contributiva, pueden ser beneficiarios del pago único para formar parte de estos nuevos proyectos empresariales, aunque la ley también permite la opción de integrarse en alguna empresa que ya esté en funcionamiento.

En el ámbito de la Economía Social encontramos que la mayoría de sus emprendedores cuentan con experiencia laboral (Plaza-Angulo, 2011) ya que, en multitud de ocasiones, se constituyen por profesionales que han perdido su puesto de trabajo habitual (Ciruela et al., 2016). Es decir, al provenir del mercado laboral muchos de ellos han generado derecho a percibir una prestación por desempleo que llegado el punto de querer emprender pueden capitalizar para financiar el inicio de la actividad.

${ }^{*}$ EI contenido de este trabajo forma parte del resultado científico del Proyecto de Investigación de I+D DER 2015-63701-C3-3-R "Instrumentos normativos sociales ante el nuevo contexto tecnológico 3.0" del Ministerio de Economía y Competitividad. 
La trascendencia de esta modalidad de prestación radica en las dificultades de financiación de las empresas en general, y en concreto de las de Economía Social, y en el hecho de que la inversión en este tipo de empresas puede generar efectos en empleo muy superiores a la media global (Fuentes y Mainar, 2015). Estudios previos ya han señalado la falta de financiación como uno de los principales problemas de estas empresas (Coll y Cuñat, 2006; Plaza-Angulo, 2011; Álamo et al., 2015), lo que se une al hecho de que la principal vía de financiación de las sociedades laborales a la hora de iniciar su actividad sea la aportación personal de cada uno de los socios (Plaza-Angulo, 2011). Por ello, la utilización de la prestación de desempleo en su modalidad de pago único se podría configurar como una importante herramienta de financiación, siendo ésta la hipótesis sobre la que gira el presente trabajo.

En definitiva, la importancia de esta modalidad de pago en la prestación por desempleo se ha puesto de manifiesto en numerosos estudios previos (Martín et al., 2005; Coll y Cuñat, 2006; Álvarez y Plaza, 2008; Lejarriaga et al., 2010; Martín, 2010, Plaza-Angulo, 2011; Lejarriaga et al., 2013; Serrano, 2014; Álamo et al., 2015; Sanchis et al., 2015; Ciruela et al., 2016). Apoyándonos en dichos estudios e investigaciones, podemos afirmar que el pago único de prestación por desempleo es la ayuda que contribuye de forma generalizada a la financiación inicial de las cooperativas y sociedades laborales, contribuyendo a la creación de empleo estable. Para demostrar esta hipótesis a lo largo de este trabajo abordamos la descripción del marco jurídico de la prestación, una revisión de la literatura sobre el tema y el análisis de los datos del Ministerio de Empleo y Seguridad Social, para finalmente desarrollar un cuestionario propio que nos ofrece datos complementarios que hacen posible contrastar la información previa y la hipótesis enunciada.

\title{
2. Régimen Jurídico y repercusión de la prestación por desempleo en su modalidad de pago único en las cooperativas y sociedades laborales
}

\author{
2.1. Régimen jurídico de la prestación de desempleo en su modalidad de pago \\ único \\ El pago único es una herramienta utilizada en el abono de la prestación por desempleo como \\ medida de fomento del autoempleo. Estas medidas encuentran respaldo legal en el artículo 129.2 \\ de la Constitución, donde se dispone que los poderes públicos han de promover las formas de parti- \\ cipación en la empresa, especialmente las cooperativas, así como que se "establecerán los medios \\ que facilite el acceso de los trabajadores a la propiedad de los medios de producción".
}




\section{Tabla 1. Normativa reguladora de la prestación de desempleo en su modalidad de pago único}

\begin{tabular}{|c|c|}
\hline $\begin{array}{l}\text { Constitución Española de 1978, de } 29 \text { de diciem- } \\
\text { bre de } 1978 .\end{array}$ & $\begin{array}{l}\text { El sustrato jurídico en el que se fundamentan las enti- } \\
\text { dades de la economía social reside en el art. 1.1, art. } \\
9.2 \text {, art. } 35 \text {, art. } 38 \text {, art. } 40 \text {, art. } 41 \text {, art. } 47 \text { y art. } 129.2 \text {. }\end{array}$ \\
\hline $\begin{array}{l}\text { Real Decreto 1044/85, de } 19 \text { de junio, por el que } \\
\text { se regula el abono de la prestación por desem- } \\
\text { pleo en su modalidad de pago único por el valor } \\
\text { actual de su importe como medida de fomento del } \\
\text { empleo. }\end{array}$ & $\begin{array}{l}\text { Norma de desarrollo que regula el abono de la presta- } \\
\text { ción de desempleo en su modalidad de pago único } \\
\text { como medida de fomento de empleo en lo que no se } \\
\text { oponga a lo establecido en la Ley de Economía Social. }\end{array}$ \\
\hline Ley 5/2011, de 29 de marzo, de Economía Social. & $\begin{array}{l}\text { Define el concepto de economía social estableciendo } \\
\text { un marco jurídico común para todo el territorio nacional } \\
\text { y contempla todo un conjunto de medidas de apoyo a } \\
\text { las empresas de trabajo asociado como el caso de la } \\
\text { prestación por desempleo en su modalidad de pago } \\
\text { único. }\end{array}$ \\
\hline $\begin{array}{l}\text { Ley } 31 / 2015 \text {, de } 9 \text { de septiembre, por la que se } \\
\text { modifica y actualiza la normativa en materia de } \\
\text { autoempleo y se adoptan medidas de fomento y } \\
\text { promoción del trabajo autónomo y de la Economía } \\
\text { Social. }\end{array}$ & $\begin{array}{l}\text { Responde a la necesidad de actualizar y sistematizar } \\
\text { la normativa existente en materia de autoempleo y } \\
\text { economía social, reformando parte del articulado de la } \\
\text { Ley del Estatuto del Trabajo Autónomo de } 2007 \text { y la } \\
\text { Ley de Economía Social de } 2011 .\end{array}$ \\
\hline $\begin{array}{l}\text { Real Decreto Legislativo 8/2015, de } 30 \text { de octu- } \\
\text { bre, por el que se aprueba el texto refundido de la } \\
\text { Ley General de la Seguridad Social. }\end{array}$ & $\begin{array}{l}\text { Texto en el que se integran, debidamente regulariza- } \\
\text { das, aclaradas y armonizadas, la Ley General de la } \\
\text { Seguridad Social del Real Decreto Legislativo 1/1994, } \\
\text { de } 20 \text { de junio, y todas las disposiciones legales rela- } \\
\text { cionadas y sus modificaciones. En su art. } 296.3 \text { se } \\
\text { ocupa del pago único de la prestación por desempleo. }\end{array}$ \\
\hline
\end{tabular}

FUENTE: Elaboración propia.

En relación al pago único de la prestación por desempleo, en un primer momento, la Ley 31/1984, de 2 de agosto, sentó las bases para el desarrollo de este instrumento, señalando en su artículo 23.3 que "cuando así lo establezca un programa de fomento de empleo, la Entidad Gestora podrá abonar de una sola vez el valor actual del importe de la prestación de nivel contributivo, correspondiente al periodo a que tenga derecho el trabajador en función de las cotizaciones efectuadas". Un año más tarde, en 1985, el Real Decreto 1044/85, de 19 de junio, posibilitó por primera vez la prestación por desempleo en su modalidad de pago único. Desde entonces han sido muchas las reformas llevadas a cabo, la última introducida por la Ley $31 / 2015$, de 9 de septiembre. Este entramado normativo ha configurado el régimen jurídico actual por el que se rige y al que en este artículo sólo hacemos refe- 
rencia de manera sucinta en lo necesario para comprender el concepto y naturaleza de la prestación. Consecuentemente, en la actualidad el régimen jurídico de la capitalización de la prestación por desempleo para la constitución de entidades de economía social (cooperativas y sociedades laborales) o su incorporación como socios en las mismas se encuentra en el art. 296.3 de la Ley General de Seguridad Social, en el art. 10 de la Ley de Economía Social y en el Real Decreto 1044/1985, en aquello que no se oponga a lo establecido en dicho art. 10 de la Ley de Economía Social (ver tabla 1)

En palabras de Álvarez y Plaza-Angulo (2008) se trata de una medida para fomentar y facilitar iniciativas de autoempleo, a través del abono del valor actual del importe de la prestación por desempleo de nivel contributivo a los beneficiarios de prestaciones que pretenden incorporarse, de forma estable, como socios trabajadores o de trabajo en cooperativas o en sociedades laborales, constituirlas, o que quieren desarrollar una nueva actividad como trabajadores autónomos. Su propia naturaleza hace de ella una medida restrictiva en cuanto al colectivo con derecho a la misma, ya que sólo será posible cuando los beneficiarios tengan derecho a una prestación por desempleo, de nivel contributiva y pendiente de percibir (Martín, 2010; Rico, 2013), y no hayan impugnado judicialmente el despido que da origen a su situación de desempleo (Serrano, 2014).

Es decir, se configura como una prestación de la Seguridad Social, que no de una ayuda o subvención, a la que hay que tener derecho para poder optar a ella. Como señalan Cañal y Rubio (2003), a pesar de ser un programa de fomento del empleo, es destinado exclusivamente a aquellos trabajadores que tienen derecho a percibir la prestación por desempleo y la cuantía será exclusivamente la que le corresponda en función de su cotización. Por lo tanto, se nos presenta como una medida de fomento del empleo limitada, que beneficia a los trabajadores que han disfrutado de cierta estabilidad laboral en el período anterior a la solicitud. Por ello, los trabajadores sujetos a la flexibilidad del mercado de trabajo, a las formas de contratación precaria, (contratos a tiempo parcial, contratos temporales, contratos fijos-discontinuos, etc.) tienen muchas dificultades para acceder al pago único de la prestación por desempleo y, de hacerlo, su cuantía es, en la mayoría de los casos, insignificante (Moreno, 1997).

En consecuencia, podemos afirmar que los estrictos requisitos legales para tener derecho a esta prestación se constituyen como importantes barreras. Estos requisitos son los siguientes:

- Ser beneficiario de una prestación contributiva por desempleo y tener pendiente de recibir, a fecha de solicitud al menos, tres mensualidades. Lo cual nos muestra claramente el carácter profesional de los socios que pueden acogerse a esta ayuda para emprender, como se ha señalado con anterioridad.

- No haber hecho uso de este derecho, en cualquiera de sus modalidades, en los cuatro años inmediatamente anteriores. A este respecto, López Gandía (2006) afirma que esto es debido a que se trata de dar un mínimo de plazo a la vida del nuevo proyecto empresarial y por ello el Servicio de Empleo evaluará la viabilidad del proyecto. Aun así, se trata de una limitación importante que no da 


\section{EL PAGO ÚNICO DE LA PRESTACIÓN POR DESEMPLEO COMO MEDIO DE FINANCIACIÓN INICIAL DE LAS EMPRESAS DE ECONOMÍA SOCIAL EN ESPAÑA}

margen de error al emprendedor pues si fracasa su proyecto empresarial y, aunque pueda tener derecho de nuevo a prestación por desempleo, no podrá utilizar esta modalidad para financiar un segundo intento. Además, el trabajador no podrá acceder a nuevas prestaciones por desempleo hasta que venza el período capitalizado (Cavas, 2016).

- Acreditar la incorporación como socio trabajador a una cooperativa de trabajo asociado o sociedad laboral, de nueva creación o en funcionamiento, de forma estable. Además, a diferencia de en épocas pasadas (Álvarez y Plaza-Angulo, 2008; Cavas, 2016) la ley permite que pueda darse el caso de que trabajadores que hayan mantenido un vínculo contractual previo con dichas sociedades puedan solicitar la capitalización para incorporarse de nuevo ellas y hacerlo como socios-trabajadores. Eso sí, deben cumplir con el resto de requisitos, por lo que no es una opción factible la reconversión de trabajadores de las propias cooperativas o sociedades laborales en socios trabajadores utilizando esta fórmula para financiar la adscripción al capital social pues en esos supuestos se podría incurrir en fraude de ley, sino que deben ser realmente trabajadores procedentes del desempleo.

- No haber iniciado la actividad, ya sea de constitución de la nueva sociedad o de incorporación como socio, antes de la fecha en que se presenta la solicitud de pago único. Se persigue con ello preservar una vez más la finalidad de la promoción del autoempleo precisando que en el momento en que se produzca la capitalización la persona esté realmente en desempleo (Mercader et al., 2010; Cavas, 2016).

De acuerdo con el art. 10.1 de la Ley de Economía Social, modificada recientemente por la Ley $31 / 2015$ de 9 de septiembre, el abono de la prestación se realizará de una sola vez por el importe que corresponda a las aportaciones al capital, incluyendo la cuota de ingreso, en el caso de las cooperativas, 0 al de adquisición de acciones o participaciones del capital social en una sociedad laboral y que son imprescindibles para acceder a la condición de socio. Con anterioridad el importe estaba limitado únicamente a financiar el montante inicial de la cuota de capital social necesario para adquirir la condición de socio (Álvarez y Plaza-Angulo, 2008) pero no la totalidad del aporte dinerario previsto en los estatutos y que hubiera de ingresarse aplazadamente ni las aportaciones complementarias (Cavas, 2016). En caso de que la cuantía total de desempleo a la que se tenga derecho sea mayor a lo necesario para adquirir la condición de socio, el resto del montante podrá utilizarse para subvencionar la cotización del trabajador a la Seguridad Social por el desarrollo de la nueva actividad.

2.2. La repercusión de la prestación por desempleo en su modalidad de pago único en las cooperativas y sociedades laborales

A la hora de poner en marcha un proyecto empresarial de economía social la financiación es una de las variables más importantes y de mayor dificultad en su consecución (Sanchis et al.; 2015). La falta de financiación es uno de los principales obstáculos a los que se enfrentan aquellos sujetos que deciden llevar a cabo una actividad económica (Álamo et al.; 2015). Plaza-Angulo (2011), en el seno de las sociedades laborales, demostró que un tercio de las empresas analizadas consideraban la difi- 
cultad de financiación como el principal problema al que se enfrentaban. Por otra parte, más de la mitad de estas empresas cubrió el cien por cien de la financiación inicial con capital propio, mientras que el $31 \%$ suscribió con aportaciones propias más del $50 \%$ de la financiación inicial, siendo solo un $15 \%$ las sociedades que recurrieron a alguna fuente de financiación ajena. La financiación ajena es marginal y, como argumentan Coll y Cuñat (2006), solo se produce en los casos donde es imposible comenzar el negocio sin una fuente adicional de fondos y recurriendo mayoritariamente al círculo más cercano de los socios fundadores como son sus familiares y amigos.

Para el caso de las sociedades laborales, Ciruela et al. (2016), afirman que muchos de sus emprendedores son profesionales que han perdido su puesto de trabajo habitual y que mediante la constitución de este tipo de empresas retoman su actividad profesional. Martín et al. (2010) van más allá y consideran que el origen de la mayoría de las sociedades laborales durante los últimos años ha tenido lugar gracias a la iniciativa de trabajadores desempleados que han capitalizado su prestación. Del mismo modo se pronunciaban Coll y Cuñat (2006) para el caso de las cooperativas, al señalar en su trabajo que los emprendedores suelen ser personas con experiencia técnica para los que el nuevo negocio significa la continuidad de trabajo anterior. Es decir, al ser trabajadores que previamente han desarrollado una actividad laboral, la probabilidad de tener derecho a prestación por desempleo contributiva y, por tanto, a capitalizarla para financiar el inicio de la actividad es una realidad según han demostrado estudios como el de Lejarriaga et al. (2010) o el de Plaza-Angulo (2011). En este último se demostró que la inmensa mayoría de los socios fundadores de sociedades laborales provenía de actividades profesionales previas similares a las puestas en práctica con el nuevo proyecto empresarial, aunque únicamente en el $42 \%$ de las empresas analizadas alguno de sus socios capitalizó la prestación por desempleo.

En cualquier caso, gracias a la capitalización del desempleo muchos emprendedores en economía social pueden obtener los recursos financieros necesarios para realizar su aportación al capital social o para subvencionar las cuotas a pagar a la Seguridad Social (Lejarriaga et al.; 2013). De hecho, en trabajos previos, Coll y Cuñat (2006) afirmaron que el pago único de prestación por desempleo es la ayuda que contribuye de forma generalizada a la financiación inicial de las empresas cooperativas en aquellas situaciones de cierre de empresa o del trabajo por cuenta ajena, no beneficiándose, además y con carácter general, de otro tipo de ayudas.

Por lo tanto, la importancia de esta modalidad de pago en la prestación por desempleo puede apreciarse en el resultado de distintos estudios (Martín et al., 2005; Coll y Cuñat, 2006; Álvarez y PlazaAngulo, 2008; Lejarriaga et al., 2010; Martín, 2010, Plaza-Angulo, 2011; Lejarriaga et al., 2013; Serrano, 2014; Álamo et al., 2015; Sanchis et al., 2015; Ciruela et al., 2016). Apoyándonos en dichos estudios e investigaciones previas, podemos afirmar que el pago único de prestación por desempleo es la ayuda que contribuye de forma generalizada a la financiación inicial de las cooperativas y sociedades laborales, contribuyendo a la creación de empleo estable. Afirmación que vamos a intentar comprobar mediante un análisis de la estadística ofrecida por el Ministerio de Empleo y Seguridad Social, así como con el desarrollo de un estudio propio. 


\section{Tabla 2. Principales cifras (año 2015)}

\begin{tabular}{|l|r|}
\hline Beneficiarios de prestación por desempleo contributiva & 838.392 \\
Beneficiarios totales que han capitalizado la prestación por desempleo contributiva & 142.753 \\
Beneficiarios que han capitalizado la prestación por desempleo contributiva para crear o & \\
integrarse en una cooperativa o sociedad laboral & 6.200 \\
Período medio de derecho reconocido (días) & 460 \\
Media de días usados para financiar el ingreso como socio & 165 \\
Importe medio líquido por beneficiario (€)* & 4.578 \\
Nuevas empresas de economía social & 1.663 \\
Socios de las nuevas empresas de economía social & 8.982 \\
$N^{\circ}$ medio de socios por cada nueva empresa de economía social & 5,4 \\
Total de empresas de economía social & 22.269 \\
Trabajadores de empresas de economía social & 284.843 \\
$N^{0}$ medio de trabajadores por empresa de economía social & 12,8
\end{tabular}

*No incluye el importe de cotizaciones a la Seguridad Social que el SEPE abona a los trabajadores para compensar sus cuotas

FUENTE: Elaboración propia a partir de datos Anuario de Estadísticas del Ministerio de Empleo y Seguridad Social.

Si atendemos a los datos estadísticos, en la tabla 2 se muestra un resumen de las principales cifras relacionadas con capitalización de la prestación por desempleo y la constitución de nuevas cooperativas o sociedades laborales durante el año 2015. De esta forma, del total de beneficiarios de la prestación por desempleo, 142.753 optaron por capitalizarla para emprender, lo que representa el 16,96\%. No obstante, de este montante, únicamente 6.200, un 4,36\%, lo hicieron para constituir o integrarse en una sociedad laboral o cooperativa. Es decir, que estos emprendedores en economía social suponen únicamente el $0,74 \%$ del total de beneficiarios de la prestación por desempleo. Si atendemos al número de socios observamos que la relación establecida entre éstos y el número de beneficiarios de la prestación por desempleo que la han capitalizado para emprender en economía social supone que el $59,33 \%$ de los socios fundadores de las nuevas sociedades laborales y cooperativas constituidas se beneficiaron del pago único. Sin embargo, esta afirmación no permite obtener conclusiones tajantes ya que la estadística habla de cifras generales sin identificar si ese total de beneficiarios de la prestación por desempleo que pasan a ser socios trabajadores, y que optaron por capitalizar el desempleo, han destinado su prestación a constituir una nueva sociedad o se han integrado en una ya existente. 


\section{Figura 1. Evolución del total de sociedades de economía social inscritas en la Seguridad Social y número de trabajadores}
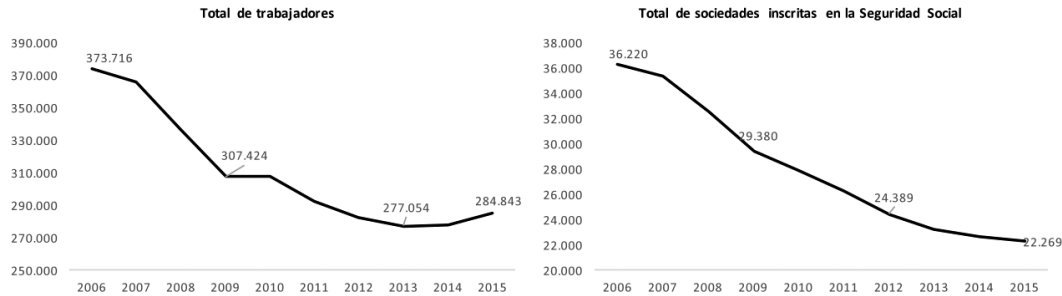

FUENTE: Elaboración propia a partir de datos Anuario de Estadísticas del Ministerio de Empleo y Seguridad Social.

Resulta interesante profundizar en el análisis de la estadística del Ministerio de Empleo y Seguridad Social para tratar de comprender la trascendencia del pago único a lo largo de los años y su relación con el emprendimiento en economía social. Una relación que no es causal, es decir, el emprendimiento en estas figuras jurídicas no depende de la existencia del pago, no configurándose como un elemento motivador, pero sí es una constante que mantiene a lo largo de los años cifras similares.

En la figura 1 podemos observar como el número de empresas de economía social se ha reducido significativamente desde el año 2006 hasta el periodo actual. Concretamente el descenso ha sido del $38,6 \%$, dejando la cifra de empresas en 22.269. Estas sociedades dan empleo a 284.842 trabajadores, incluidos los socios, lo que supone un descenso del $23,7 \%$.

\section{Figura 2. Evolución del número de trabajadores por sociedad de economía social inscritas en la Seguridad Social por empresa}

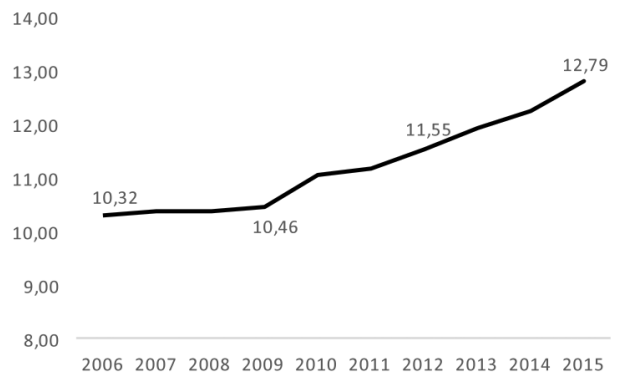

FUENTE: Elaboración propia a partir de datos Anuario de Estadísticas del Ministerio de Empleo y Seguridad Social. 


\section{EL PAGO ÚNICO DE LA PRESTACIÓN POR DESEMPLEO COMO MEDIO DE FINANCIACIÓN INICIAL DE LAS EMPRESAS DE ECONOMÍA SOCIAL EN ESPAÑA}

Este descenso es menor que el de destrucción de empresas en general y se debe, en parte, al repunte en el empleo generado por estas organizaciones desde 2013 y que difiere de la tendencia reduccionista del número de sociedades durante toda la serie. De hecho, desde 2013 el número de empresas de economía social ha descendido en un $4 \%$ mientras que el número de trabajadores ha aumentado para ese mismo período en un 2,81\%. Además, durante el período estudiado se observa (figura 2) cómo la tendencia de las empresas de economía social ha sido a aumentar su tamaño en lo relativo al número de trabajadores, pasando de 10,32 en 2006 a 12,79 en 2015, lo que supone un crecimiento del $23,9 \%$.

\section{Figura 3. Evolución del número de nuevas sociedades de economía social constituidas y número de socios fundadores}
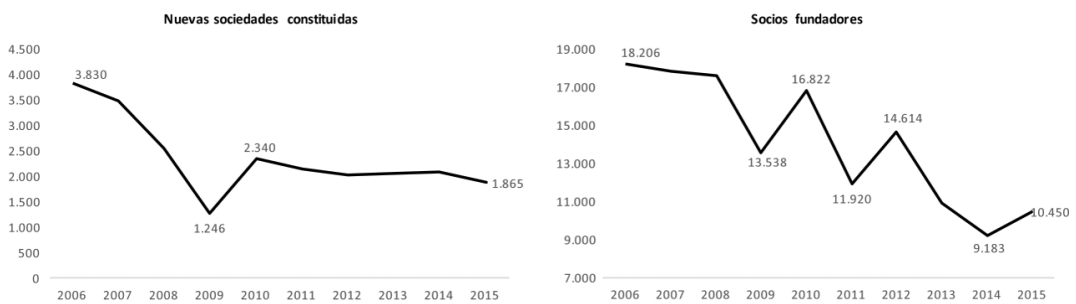

FUENTE: Elaboración propia a partir de datos Anuario de Estadísticas del Ministerio de Empleo y Seguridad Social.

En relación al número de nuevas sociedades de economía social constituidas, observamos en la figura 3 como tras la pronunciada caída comprendida entre 2006 y 2009 el número de constituciones crece y se estabiliza en el resto del período, aunque con una tendencia negativa. Así, entre 2009 y 2010 se crearon un $87,8 \%$ más de empresas de economía social y, sin embargo, desde 2010 hasta la actualidad el descenso ha sido del $20,3 \%$. En cuanto a los socios fundadores, que son los potenciales beneficiarios de la prestación por desempleo en su modalidad de pago único, comprobamos como han seguido una dinámica irregular que no siempre va de la mano del número de sociedades constituidas, lo que nos muestra la heterogeneidad de los proyectos creados en cuanto a su tamaño. Además, los datos sobre el número de socios fundadores sugieren algo más importante, y es que durante todo el período la media es de 6,3 socios por sociedad creada, muy superior a la mínima exigida por la ley durante ese periodo. 


\section{Figura 4. Causa de la situación de desempleo en 2015}

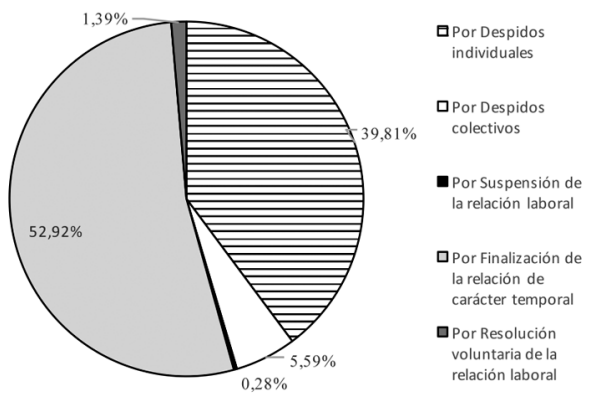

FUENTE: Elaboración propia a partir de datos Anuario de Estadísticas del Ministerio de Empleo y Seguridad Social.

Como hemos comentado anteriormente, para poder optar a esta prestación la persona debe cumplir los requisitos de la prestación por desempleo en el nivel contributivo. Las causas que propician la situación de desempleo entre los beneficiarios de estas prestaciones las podemos ver en la figura 4. Como puede observarse, en el $52,92 \%$ de los casos el trabajador llega al desempleo como consecuencia de la extinción de un contrato de trabajo de carácter temporal, y en el $39,81 \%$ de los casos lo hace como consecuencia de un despido individual, mientras que el $5,59 \%$ de las situaciones se debe a un despido colectivo. En consecuencia, comprobamos como las dos principales causas de desempleo responden claramente al modelo de precariedad laboral (temporalidad en la relaciones laborales y despidos individuales de dudosa justificación legal como medio para contratar posteriormente mano de obra más barata) instaurado en la actualidad en el mercado de trabajo y que empuja a miles de trabajadores al desempleo. De deberse a la situación de recesión o estancamiento económico los despidos colectivos deberían tener un peso mayor como reflejo del cierre de empresas 0 de reducciones drásticas de plantilla.

\section{Figura 5. Sector de actividad de procedencia de los beneficiarios de prestación por desempleo. Media 2006-2015}

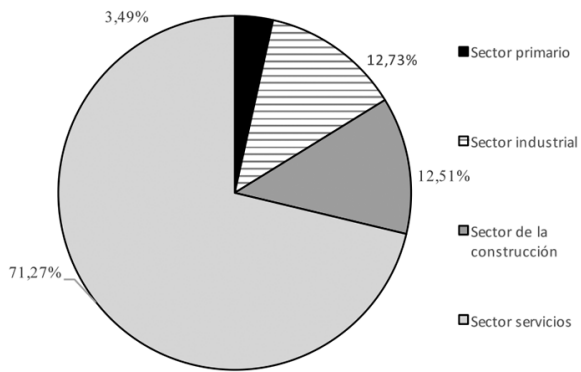

FUENTE: Elaboración propia a partir de datos Anuario de Estadísticas del Ministerio de Empleo y Seguridad Social. 


\section{EL PAGO ÚNICO DE LA PRESTACIÓN POR DESEMPLEO COMO MEDIO DE FINANCIACIÓN INICIAL DE LAS EMPRESAS DE ECONOMÍA SOCIAL EN ESPAÑA}

El sector de actividad del que suelen proceder los beneficiarios de la prestación por desempleo se asemeja a la estructura sectorial de la economía en general, aunque es mucho más acentuado el número de desempleados procedentes del sector servicios con un $71,27 \%$, mientras que el sector que aporta un menor número de desempleados es el sector primario con un 3,49\%. A la hora de saber en qué sector se utilizará la prestación por pago único para constituir o integrarse en una sociedad de economía social podría pensarse que se respetaría, con carácter general, el reparto de la figura 5. No obstante, y sin poder comprobarlo en este trabajo pero con intención de hacerlo posteriormente, el conocimiento del sector de la economía social nos hace pensar que el emprendimiento en el sector primario y en el industrial será mucho mayor que lo reflejado por el aporte de potenciales usuarios de la capitalización del desempleo.

\section{Figura 6. Evolución de la tasa de variación anual de los beneficiarios de prestación por desempleo y los beneficiarios que optaron por el pago único}

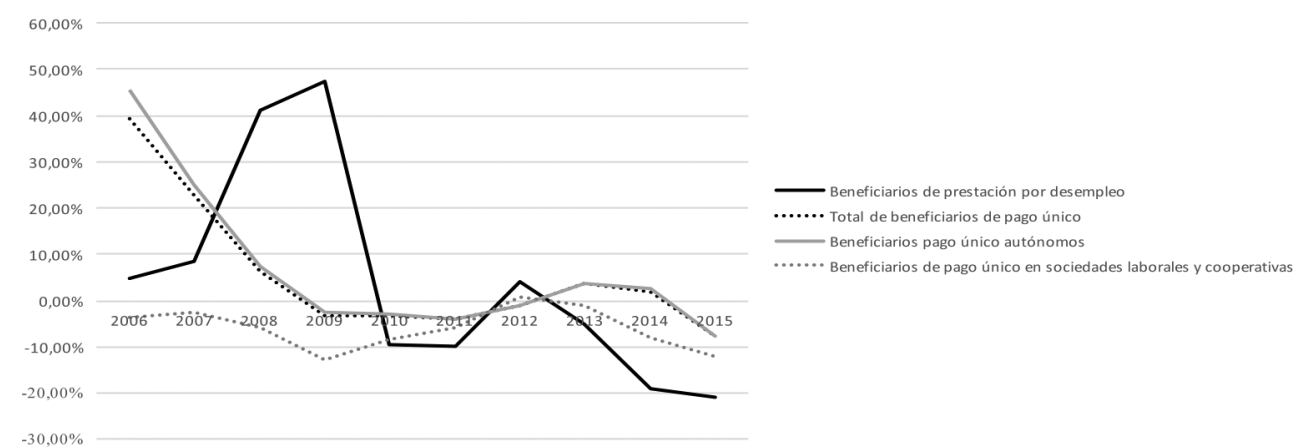

FUENTE: Elaboración propia a partir de datos Anuario de Estadísticas del Ministerio de Empleo y Seguridad Social.

En la figura 6 se muestra la evolución de la tasa de variación anual durante el período 2006-2015 para las variables "beneficiarios de prestación por desempleo", que constituye el potencial de aquellos que tienen derecho a capitalización, "total de beneficiarios de pago único", que son los que lo han hecho efectivo para cualquiera de las opciones existentes, "beneficiarios de pago único autónomos" y "beneficiarios en sociedades laborales y cooperativas". La primera cuestión que debemos resaltar es que la evolución del número de beneficiarios de la prestación por desempleo en su nivel contributivo parece no condicionar, al menos durante toda la serie, el volumen de beneficiarios de pago único. Así, entre 2006 y 2009 el número de beneficiarios de prestación por desempleo tuvo un crecimiento acumulado del $97 \%$, mientras que los beneficiarios que optaron por capitalizar la prestación sufrieron un aumento del $25,75 \%$, con tasas negativas durante 2009 para el total y durante estos tres años para aquellos que se integraban o constituían una cooperativa o sociedad laboral (-21\%). Sin embargo, a partir de 2011 sí parece haber cierta correlación entre estas variables dibujando tendencias similares que pasan por un aumento en 2012 y un descenso continuado hasta 2015. 
Si atendemos a datos absolutos comprobamos como el año con un mayor número de beneficiarios de pago único fue 2008 (figura 7). Sin embargo, aquellos sujetos que capitalizaron la prestación para formar parte de una cooperativa o sociedad laboral encuentra su máximo en 2006 y desde ese ejercicio comienza un descenso que se aleja de la tendencia del total de beneficiarios, de aquellos que lo hacen para constituirse como trabajadores autónomos y del número de perceptores de prestación por desempleo. De hecho, en 2015 ha habido 4.968 beneficiarios menos de la prestación por desempleo en su modalidad de pago único para formar parte de una cooperativa o sociedad laboral, lo que supone un descenso del $55,51 \%$, mientras que el caso de los beneficiarios del pago único que lo utilizaron para convertirse en trabajadores autónomos, hablamos de un ascenso del $18,51 \%$. Lo importante de esto, desde nuestro punto de vista, no es el número absoluto, pues históricamente el número de perceptores de desempleo que han optado en capitalizar para emprender ha sido superior en el caso de los autónomos, sino la tendencia que nos muestra cómo mientras los emprendedores autónomos logran mantenerse, los emprendedores colectivos en economía social descienden de manera preocupante.

\section{Figura 7. Evolución de los beneficiarios de prestación por desempleo y los beneficiarios que optaron por el pago único (datos absolutos)}

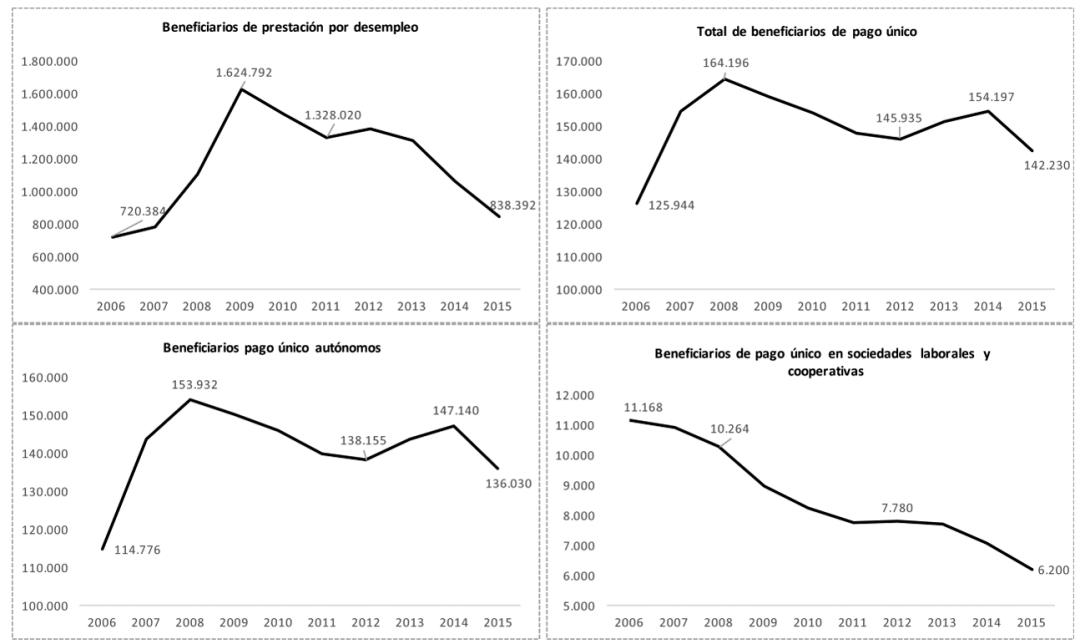

FUENTE: Elaboración propia a partir de datos Anuario de Estadísticas del Ministerio de Empleo y Seguridad Social.

Por otro lado, la figura 8 muestra una comparativa en la evolución del número de socios fundadores de nuevas empresas de economía social y el número de perceptores de pago único para estas figuras jurídicas. La tendencia a lo largo de la serie es, para ambas variables, negativa, con un descenso entre 2006 y 2009 del $42,6 \%$ en el caso del número de socios fundadores y del $44,5 \%$ del número de beneficiarios de pago único. Como puede apreciarse en el supuesto de los beneficiarios 


\section{EL PAGO ÚNICO DE LA PRESTACIÓN POR DESEMPLEO COMO MEDIO DE FINANCIACIÓN INICIAL DE LAS EMPRESAS DE ECONOMÍA SOCIAL EN ESPAÑA}

del pago único la tendencia es regular a lo largo de todo el período, mientras que, sin embargo, en el caso de los socios fundadores, la irregularidad, con continuas subidas y bajadas, es la nota dominante, aunque como hemos indicado, con un resultado final negativo durante el período de referencia.

\section{Figura 8. Evolución del número de socios fundadores y beneficiarios de pago único en empresas de economía social de nueva creación}

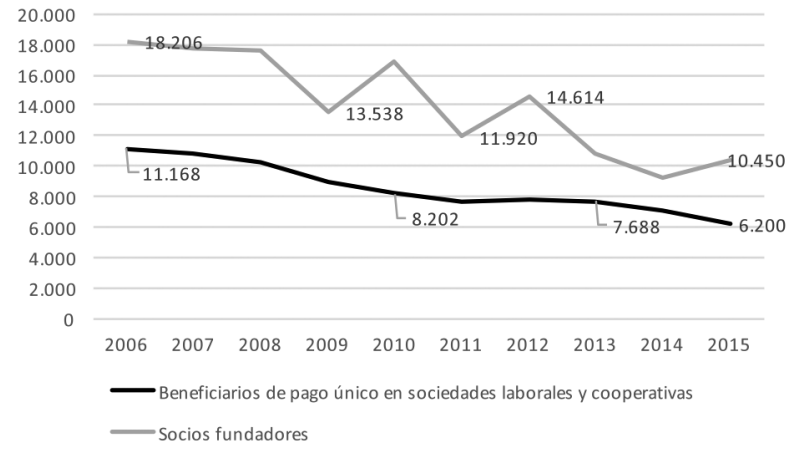

FUENTE: Elaboración propia a partir de datos Anuario de Estadísticas del Ministerio de Empleo y Seguridad Social.

Por último, en la figura 9 se representa el porcentaje de socios fundadores que han capitalizado su prestación para la constitución de una empresa de economía social. Como puede apreciarse, salvo en 2010, para el resto de años más de la mitad de los socios fundadores han capitalizado su prestación por desempleo, siendo el año 2014 en el que hubo una mayor proporción (76,8\%). Durante el período estudiado la media de socios fundadores que han capitalizado su prestación ha sido del $62 \%$.

\section{Figura 9. Evolución del \% de socios fundadores con capitalización del pago único en empresas de economía social}

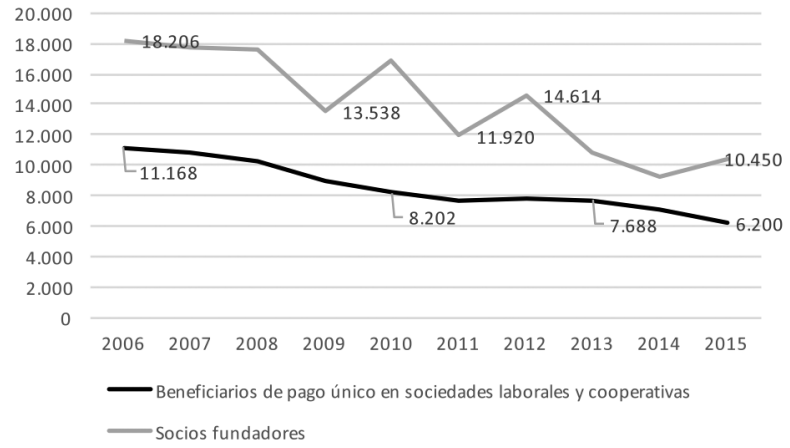

FUENTE: Elaboración propia a partir de datos Anuario de Estadísticas del Ministerio de Empleo y Seguridad Social. 
En este sentido, la tabla 3 muestra la configuración básica de la prestación obtenida por los trabajadores que han capitalizado su prestación. La prestación por desempleo tiene dos componentes esenciales: la cuantía y el período durante el que se tiene derecho a percibirla. La primera depende de la base de cotización (ligada al salario) y el segundo del período cotizado. De este modo, comprobamos como el período medio de derecho reconocido es de 493,1 días que se corresponden con una cuantía total a percibir de 14.197,27 euros. Sin embargo, esta no es la cuantía que se permite sea utilizada para financiar la incorporación como socio trabajador a una empresa de economía social pues, como se ha explicado en epígrafes anteriores, tanto la legislación como la jurisprudencia han sido muy estrictas al respecto dando lugar únicamente al montante necesario para ser socio. Por ello, el número medio de días de prestación capitalizados para formar parte de una empresa de economía social es de 153,5 y la cuantía equivalente a dichos días es de 4.418,8 euros.

\section{Tabla 3. Características de la prestación de pago único. Media del período 2006-2015}

\begin{tabular}{|l|c|l|c|}
\hline $\begin{array}{l}\text { Período medio de derecho reconocido } \\
\text { en días }\end{array}$ & 493,10 & $\begin{array}{l}\text { Número medio de días capitalizados por beneficiario } \\
\text { para formar parte de una empresa de economía social }\end{array}$ & 153,50 \\
\hline $\begin{array}{l}\text { Importe medio capitalizado por beneficiario para financiar su participación como socio } \\
\text { en la empresa de economía social }(€)\end{array}$ & $4.417,80$ \\
\hline $\begin{array}{l}\text { Importe total medio al que } \\
\text { tiene derecho }(€)\end{array}$ & $14.197,27$ & $\begin{array}{l}\text { Importe que puede ser destinado a compensación } \\
\text { de cuotas a la Seguridad Social ( }(€)\end{array}$ & $9.779,47$ \\
\hline
\end{tabular}

FUENTE: Elaboración propia a partir de datos Anuario de Estadísticas del Ministerio de Empleo y Seguridad Social.

Por último, la figura 10 muestra la diferencia existente en la cuantía percibida por día en las distintas comunidades autónomas respecto de la media nacional. Hemos creído oportuno incorporar estas referencias por la gran disparidad existente que condicionan el importe de esta prestación vital para los emprendedores. Como puede observarse la diferencia es muy significativa; mientras que en comunidades autónomas como el País Vasco o Navarra se percibe más de un 16\% de prestación que la media, en el otro extremo, en Extremadura o Canarias se percibe un 10\% menos. Si traducimos estos porcentajes a cantidades, comprobamos como en Navarra un trabajador con derecho a prestación por desempleo puede percibir, para cubrir los gastos de ingreso como socio en una empresa de economía social, hasta 1.186,55 euros más de media, es decir, una prestación un $24 \%$ superior. Sin duda, esta realidad es reflejo de la disparidad salarial existente entre las distintas regiones de nuestro país que se manifiesta en las bases de cotización y, posteriormente, en las prestaciones de la Seguridad Social. 


\section{Figura 10. Diferencia en porcentaje de la cuantía media por día de la prestación capitalizada por comunidades autónomas en 2015}

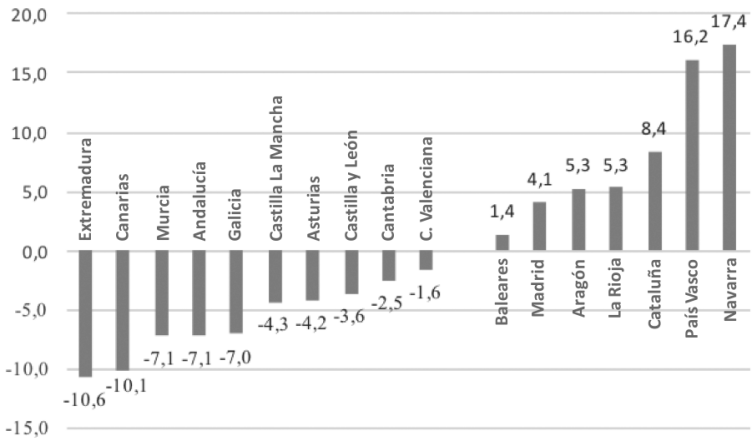

FUENTE: Elaboración propia a partir de datos Anuario de Estadísticas del Ministerio de Empleo y Seguridad Social.

\section{Análisis de la utilización del Pago Único en Empresas de Economía Social}

\subsection{Metodología}

Una vez analizado el marco jurídico de la prestación por desempleo en su modalidad de pago único, así como las evidencias, por parte de la literatura, sobre la importancia de esta prestación para la creación de nuevas sociedades laborales y cooperativas, así como las principales cifras de la estadística oficial del Ministerio de Empleo y Seguridad Social, creemos necesario profundizar en la aportación de datos para poder construir una descripción más cercana aún al fenómeno estudiado. Para ello, hemos realizado un análisis cuantitativo basado en un cuestionario telefónico y cuya población objeto de estudio son las sociedades laborales y cooperativas en España, excluyendo de estas últimas a las cooperativas de viviendas, cooperativas de consumidores y cooperativas de segundo y posterior grado, pues consideramos que la naturaleza de estas figuras difiere de aquellas que son objeto del presente trabajo. El muestreo es aleatorio pero estratificado y proporcional al número de sociedades laborales y cooperativas que forman la población (ver tabla 5).

Con este estudio se pretende dar respuesta a cuestiones tales como el capital social o el desembolso inicial necesario para constituir la empresa o para formar parte de ella como socio, al modo en que se financió el inicio de la actividad empresarial, al número de socios que han capitalizado la pres- 
tación por desempleo para formar parte de la empresa, la cuantía que se ha capitalizado, al hecho de si el pago único ha sido determinante para constituir la empresa o integrarse en ella, así como si se ha obtenido algún otro tipo de ayuda o subvención pública para iniciar la actividad empresarial o para incorporar nuevos socios al proyecto.

\section{Tabla 4. Ficha Técnica}

\begin{tabular}{|lr|}
\hline Universo & 22.269 sociedades laborales y cooperativas \\
Ámbito geográfico & España \\
Tamaño de la muestra & 378 \\
Metodología & Muestreo aleatorio simple \\
Herramienta & Encuesta telefónica \\
Error muestral & $+/-5 \%$ \\
Nivel de confianza & Abril y Mayo de 2016 \\
Período de recogida de datos & $95 \% \mathrm{Z}=1,96 ;$ Alfa $=0,05 ; \mathrm{P}=\mathrm{Q}=50 \%$ \\
\hline
\end{tabular}

FUENTE: Elaboración propia.

Se ha tomado como referencia un universo conformado por 10.313 sociedades laborales y 11.956 cooperativas, es decir, 22.269 empresas de economía social ubicadas en España según datos del Ministerio de Empleo y Seguridad Social en 2015. Para calcular el tamaño de la muestra, y tratándose de una población finita menor o igual que 100.000, hemos utilizado la fórmula propuesta por Bello, Vázquez y Trespalacios (1993), con un valor de confianza del $95 \%$ y un margen de error del $5 \%$, en el que la probabilidad a favor y en contra será del $50 \%$.

\section{Tabla 5. Procedencia de la muestra}

\begin{tabular}{|l|ccc|}
\hline & Población & Porcentaje & Muestra \\
\hline Sociedades Laborales & 10.313 & $46,31 \%$ & 176 \\
Cooperativas & 11.956 & $53,69 \%$ & 202 \\
Total & 22.269 & $100 \%$ & 378 \\
\hline
\end{tabular}

FUENTE: Elaboración propia.

El muestreo es estratificado y proporcional al número de sociedades laborales y cooperativas que forman la población, como se muestra en la tabla 4. Así, la muestra es de un total de 378 empresas, de las cuales 176 son sociedades laborales y 202 son sociedades cooperativas. La elección sobre qué empresas seleccionar para el cuestionario ha sido al azar, mediante una elección probabilística aleatoria simple. 


\section{EL PAGO ÚNICO DE LA PRESTACIÓN POR DESEMPLEO COMO MEDIO DE FINANCIACIÓN INICIAL DE LAS EMPRESAS DE ECONOMÍA SOCIAL EN ESPAÑA}

\subsection{Resultados}

\section{a) Datos identificativos}

Respecto a la antigüedad de las empresas analizadas, con los datos obtenidos se pueden clasificar en tres grandes intervalos siguiendo el criterio de Arcas et al. (2016), de manera que nos encontramos con una realidad especialmente significativa como es que el $46,10 \%$ de las empresas encuestadas tienen menos de 15 años, pasando la cifra al $31,3 \%$ para aquellas que tienen entre 16 y 30 años, y reduciéndose al 22,6\% para las que presentan una antigüedad superior a 30 años, lo cual nos hace pensar en una revitalización progresiva del sector.

\section{Figura 11. Antigüedad de la empresa de economía social}

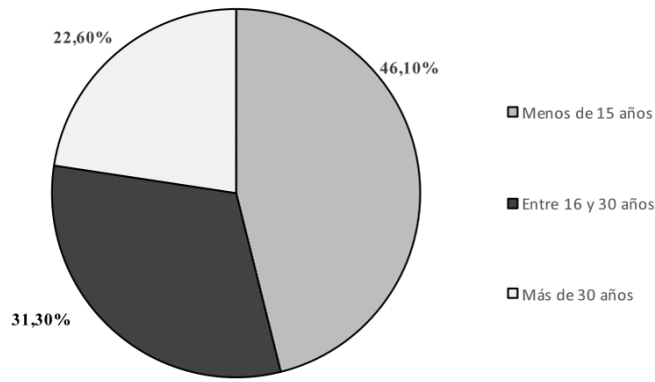

FUENTE: Elaboración propia.

En cuanto al sector de actividad, siguiendo la tendencia de las sociedades industrializadas en la actualidad, el 49,9\% de las empresas de economía social encuestadas forman parte del gigantesco sector servicios, lo cual pone de manifiesto la importancia de las sociedades laborales y de las cooperativas de trabajo asociado dentro del mismo. Cabe destacar también la presencia, que además es tradicional, de las empresas de economía social en el ámbito del sector primario, especialmente las cooperativas agrarias. El peso del sector industrial es del $20,20 \%$ y, por último, la construcción representa un 12,6\% impulsado principalmente por sociedades laborales. Cabe recordar, como hemos explicado en apartados anteriores, que en este trabajo no se han considerado como empresas de economía social las cooperativas de viviendas, por lo que estas cifras corresponden únicamente a empresas que prestan sus servicios para terceros en este sector. 


\section{Figura 12. Sector de actividad}

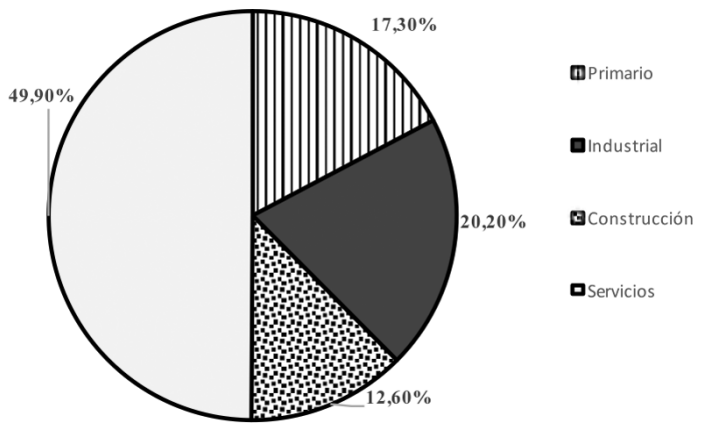

FUENTE: Elaboración propia.

Los datos sobre el capital social de estas empresas nos muestran que, con carácter general, se trata de pequeñas empresas. Aunque la media del capital social es superior a los treinta y un mil euros, si atendemos al dato de la mediana, que evita los valores extremos, comprobamos como éste desciende hasta los cuatro mil quinientos euros. Si tenemos en cuenta que estas empresas cuentan con 9,9 socios trabajadores de media, según datos de nuestra encuesta, encontramos que, aunque tomemos de referencia la media del capital social, el aporte necesario para ingresar como socio en una empresa ya constituida o para constituirla no supone desembolsos excesivamente altos. Esto explica lo que señalan algunos estudios previos como el de Coll y Cuñat (2006) o Plaza-Angulo (2011), en el sentido que son empresas que suelen recurrir poco a la financiación ajena a la hora de abordar la financiación de su capital social.

\section{Tabla 6. Capital social}

\begin{tabular}{|l|r|}
\hline Media & $31.040,72 €$ \\
\hline Mediana & $4.502,50 €$ \\
\hline
\end{tabular}

FUENTE: Elaboración propia.

\section{b) Financiación}

Como se muestra en la figura 13 , el $63,8 \%$ de las empresas encuestadas manifiestan que financiaron más del $76 \%$ de su capital inicial con aportaciones propias de los socios. Además, el $20,1 \%$ financió el capital inicial con aportaciones propias que suponían entre 51 y el $75 \%$ del desembolso necesario, representando un $9,8 \%$ las que financiaron de esta manera entre el 26 y el $50 \%$ y reduciéndose a un $6,3 \%$ aquellas en las que las aportaciones personales de los socios juegan un papel marginal. 


\section{Figura 13. Financiación inicial con aportaciones propias de los socios}

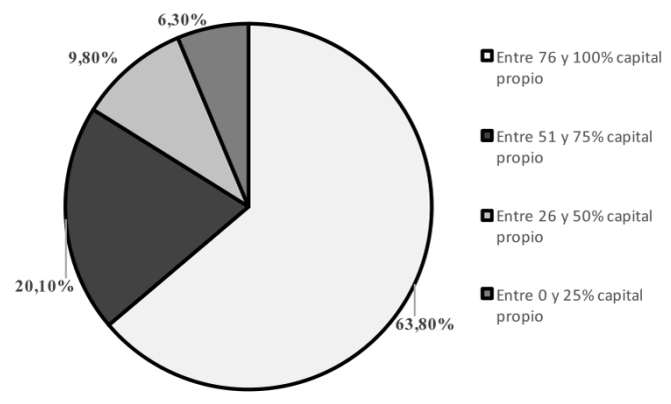

FUENTE: Elaboración propia.

Llegados a este punto llega la hora de saber si esas aportaciones propias son cubiertas por la capitalización de la prestación por desempleo a la que pudieran tener derecho. En el $46,4 \%$ de los casos, los socios optaron por capitalizar su prestación por desempleo con el fin de financiar su aportación al capital social de la empresa. Constituye, por tanto, una importante vía de financiación para estas empresas. Al profundizar en el análisis comprobamos como únicamente en un 2,5\% de los casos ninguno de los socios recurrió a esta ayuda para poder financiar sus aportaciones al capital social. De hecho, en el $45,3 \%$ de los casos fue uno de sus socios el que utilizo la capitalización del desempleo, mientras que en el $35,9 \%$ lo hacían dos socios y en el $12,1 \%$ tres de ellos.

\section{Figura 14. Número de socios trabajadores que han capitalizado la prestación por desempleo}

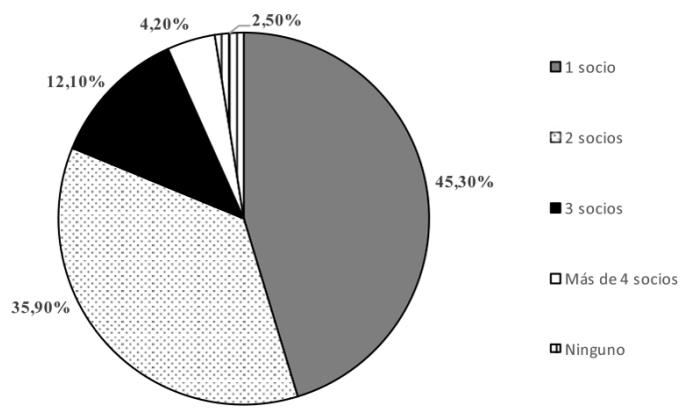

FUENTE: Elaboración propia. 
Por otro lado, también nos parece relevante saber si el hecho de poder contar con la opción de capitalizar la prestación de desempleo puede o no influir en la decisión de constituir una empresa de economía social o integrarse en una ya existente. Al ser preguntados por ello el $77,6 \%$ de los encuestados manifestó que el poder contar con el pago único fue determinante a la hora de poner en marcha el proyecto empresarial o bien para ingresar en una sociedad ya constituida. Esta respuesta pone de manifiesto la influencia que, a pesar de su cuantía, tiene en los potenciales emprendedores

\section{Tabla 7. Importe de la prestación y destino}

\begin{tabular}{|l|c|c|c|}
\hline & $\begin{array}{c}\text { Días de } \\
\text { prestación }\end{array}$ & $\begin{array}{c}\text { Cuantía } \\
\text { (euros) }\end{array}$ & Porcentaje \\
\hline Período medio de desempleo reconocido & 490 & $12.200,10$ & $100 \%$ \\
Días empleados en la cuantía necesaria para acceder a la condición de socio & 165 & $4.108,20$ & $33,67 \%$ \\
Cuantía para compensar las cuotas del trabajador a la Seguridad Social & 325 & $8.091,90$ & $66,33 \%$ \\
\hline
\end{tabular}

FUENTE: Elaboración propia.

En cuanto a la cuantía capitalizada, apoyándonos en los datos generales del Ministerio de Empleo y Seguridad Social y los datos recabados en la encuesta, estimamos que el importe total medio al que tienen derecho asciende a los 12.200,1 euros, de los cuales utilizan 4.108,2 euros (33,67\%) a cubrir la cuota de capital social y otros gastos necesarios para adquirir la condición de socio, restando una cantidad media de $8.091,9$ euros (66,33\%) para compensar las cuotas del trabajador (que no las de la empresa) a la Seguridad Social. Es decir, que el proyecto empresarial se beneficia únicamente de un $33,67 \%$ de la cuantía a la que el trabajador realmente tiene derecho. Esta cuantía, que es escasa si consideramos la necesidad de financiación inicial de cualquier proyecto empresarial, representa por el contrario la principal ayuda a la que pueden recurrir estos emprendedores, ya que al ser preguntados directamente sobre las ayudas o subvenciones a las que habían podido tener acceso, únicamente el $20,6 \%$ de las empresas encuestadas manifiestan haber disfrutado de algún otro tipo de ayuda 0 subvención pública a la hora de poner en marcha su actividad empresarial.

\section{Discusión-Conclusiones}

Según datos del Ministerio de Trabajo y Seguridad Social el sector de las empresas de economía social se encuentra en una dinámica negativa en cuanto al número de empresas, aunque con menor destrucción de empleo y donde las empresas que mantienen su actividad aumentan el número de trabajadores. Este dato demuestra la viabilidad de estas tipologías empresariales, aún en tiempos de recesión y estancamiento económico, mostrándose como un argumento de peso a la hora de que los poderes públicos consideren la necesidad de aumentar su apoyo a estas figuras. 


\section{EL PAGO ÚNICO DE LA PRESTACIÓN POR DESEMPLEO COMO MEDIO DE FINANCIACIÓN INICIAL DE LAS EMPRESAS DE ECONOMÍA SOCIAL EN ESPAÑA}

Al analizar los datos del Ministerio de Empleo y Seguridad Social sobre beneficiarios de la prestación por desempleo que deciden capitalizar su prestación, comprobamos como únicamente un 4,36\% de ellos lo hace para constituir o entrar a formar parte de una empresa de economía social. Estos datos pueden hacernos pensar que la importancia de esta prestación para las empresas de economía social es menor. Sin embargo, según datos recabados por nuestra encuesta, el $77,6 \%$ de los encuestados manifestó que el poder contar con el pago único fue determinante a la hora de poner en marcha el proyecto empresarial o bien para ingresar en una sociedad ya constituida. Con ello se pone de manifiesto, la trascendencia que, a pesar de su cuantía, tiene en los potenciales emprendedores, tal y como apuntaron autores como Coll y Cuñat (2006), Lejarriaga et al. (2010) o Plaza-Angulo (2011).

Según datos del estudio se trata de empresas que operan principalmente en el sector servicios, lo que evidencia la importante presencia de sociedades laborales y cooperativas de trabajo asociado, aunque cuentan también con importante presencia en el sector primario, debido especialmente a las cooperativas agrarias. Cuentan con un capital social medio superior a los treinta y un mil euros, con una mediana para esta variable de cuatro mil quinientos euros. Cifras modestas que se reflejan en el hecho de que son empresas que suelen recurrir poco a la financiación ajena a la hora de abordar la financiación de su capital social, con lo que se corrobora de esta forma lo descrito por la literatura en trabajos anteriores respecto de la dificultad de recurrir a financiación ajena y, por tanto, la utilización casi exclusiva de aportaciones personales (Coll y Cuñat, 2006; Plaza-Angulo, 2011; Álamo et al., 2015; Sanchis et al., 2015). De hecho, según nuestros resultados en el $63,4 \%$ de los casos los socios suscribieron por encima del $76 \%$ del capital social de la empresa con ahorros personales.

En relación a los socios fundadores, que son los potenciales beneficiarios de la prestación por desempleo en su modalidad de pago único, comprobamos como, según el Ministerio de Trabajo y Seguridad Social, presentan una dinámica irregular que difiere en ocasiones del número de sociedades constituidas, lo que muestra la heterogeneidad de los proyectos creados en cuando a su tamaño. Además, durante el período 2006-2015 la media es de 6,3 socios por sociedad creada, cifra superior al mínimo exigido por la ley para poder constituir estas sociedades y que nos lleva a pensar que se crean proyectos con una razón empresarial detrás y no únicamente como mecanismos de captación de ayudas o bonificaciones ligados a estas tipologías sociales. Al casar los resultados de nuestra encuesta, comprobamos como el número medio de socios por empresa se eleva a los 9,9, con lo que se vislumbra que las empresas de economía social son proyectos empresariales que tienden al crecimiento.

Según datos del estudio, en el 46,4\% de los casos, los socios optaron por capitalizar su prestación por desempleo con el fin de financiar su aportación al capital social de la empresa. Tan sólo en un 2,5\% de las empresas ninguno de los socios recurrió a esta ayuda para poder financiar sus aportaciones al capital social. Constituye, por tanto, en línea con lo que dicen estudios previos (Lejarriaga et al., 2010; Plaza-Angulo, 2011; Lejarriaga et al., 2013), una importante vía de financiación para estas empresas, aunque sin llegar a las cifras referidas por Martín et al. (2010) en su estudio sobre sociedades laborales. 
Conforme a los resultados, cada uno de los socios que capitalizó su prestación por desempleo lo hizo por un valor medio de 4.108,2 euros. Esta cuantía, que es escasa si consideramos la necesidad de financiación inicial de cualquier proyecto empresarial, representa por el contrario la principal ayuda a la que pueden recurrir estos emprendedores, tal y como señalaron Coll y Cuñat (2006) o PlazaAngulo y Rico (2013) y como contrastamos con los datos de nuestro estudio al comprobar que únicamente el 20,6\% de las empresas encuestadas han disfrutado de algún otro tipo de ayuda 0 subvención pública a la hora de poner en marcha su actividad empresarial. Pero, además, supone un trato desigual frente a los beneficiarios que se constituyen como trabajadores autónomos y que sí pueden usar el total de su capitalización para financiar los gastos e inversiones necesarias para iniciar su actividad.

Por todo lo anterior, y en función de los datos y comentarios expuestos a lo largo del presente trabajo, estamos en disposición de aceptar la hipótesis planteada y, por tanto, afirmar que el pago único por prestación por desempleo es la ayuda que contribuye de forma generalizada a la financiación inicial de las cooperativas y sociedades laborales, favoreciendo, por tanto, la creación de empleo estable. Es por ello por lo que animamos a los poderes públicos a potenciar y desarrollar este tipo de incentivos.

\section{Referencias bibliográficas}

ÁLAMO CERRILLO, R. \& ROMERO FLOR, L.M. (2015): "La Ley de emprendedores y su efectividad", Boletín económico de ICE, Información Comercial Española, 3059, 51-59.

ÁLVAREZ CORTÉS, J.C. \& PLAZA-ANGULO, J.J. (2008): "El desempleo en su modalidad de pago único como ayuda a nuevos emprendedores", Temas laborales: Revista andaluza de trabajo y bienestar social, 95, 283-296.

ARCAS LARIO, N., GARCÍA PÉREZ DE LEMA, D., MARTÍNEZ VICTORIA, M.C. \& MATÉ SÁNCHEZ DE VAL, M.L. (2016): Diagnóstico económico y financiero de las cooperativas agroalimentarias en España 2011/2013, Cajamar.

CAÑAL RUIZ, J.M. \& RUBIO MEDINA, M.D. (2003): "El pago único de la prestación por desempleo: régimen jurídico y novedades introducidas por la Ley 45/2002", Temas laborales: Revista andaluza de trabajo y bienestar social, 68, 108-109.

CAVAS MARTíNEZ, F. (2016): "La capitalización de las prestaciones por desempleo y el cese de actividad como medidas de fomento del emprendimiento social", Revista General de Derecho del Trabajo y de la Seguridad Social, 43, 2. 


\section{EL PAGO ÚNICO DE LA PRESTACIÓN POR DESEMPLEO COMO MEDIO DE FINANCIACIÓN INICIAL DE LAS EMPRESAS DE ECONOMÍA SOCIAL EN ESPAÑA}

CIRUELA LORENZO, A., CUADRADO SERRÁN, M. \& PLAZA-ANGULO, J.J. (2016): "La economía social como alternativa de autoempleo. El perfil del emprendedor/a en las sociedades laborales andaluzas", REVESCO, Revista de Estudios Cooperativos, 122.

COLL SERRANO, V. \& CUÑAT GIMÉNEZ, R. (2006): "Análisis de los factores que influyen en el proceso de creación de una cooperativa de trabajo asociado", REVESCO, Revista de Estudios Cooperativos, 88, 128-161.

CHAVES ÁVILA, R. \& SAVALL MORERA, T. (2013): "La insuficiencia de las actuales políticas de fomento de cooperativas y sociedades laborales frente a la crisis en España", REVESCO, Revista de Estudios Cooperativos, 113, 61-91.

FAJARDO GARCÍA, G. (2012): "El fomento de la 'economía social' en la legislación española", REVESCO, Revista de Estudios Cooperativos, 107, 58.

FUENTES SAGUAR, P.D. \& MAINAR CAUSAPÉ, A.J. (2015): "Impacto económico y en el empleo de la Economía Social en España. Un análisis multisectorial", CIRIEC-España, Revista de Economía Pública, Social y Cooperativa, 83, 63.

HERNÁNDEZ, S.B. \& RODRIGO, J.R. (2009): "La creación de puestos de trabajo para el desarrollo profesional de las personas mayores de cuarenta años: el microemprendimiento", REVESCO, Revista de Estudios Cooperativos, 98, 7-34.

LEJARRIAGA PÉREZ DE LAS VACAS, G., BEL DURÁN, P. \& MARTíN LÓPEZ, S. (2013): "El emprendimiento colectivo como salida laboral de los jóvenes: análisis del caso de las empresas de trabajo asociado", REVESCO, Revista de Estudios Cooperativos, 112, 36.

LEJARRIAGA, G. \& MARTíN, S. (2010): "Las sociedades laborales". En: Monzón, J.L. (Dir.), La Economía Social en España en el año 2008, CIRIEC-España, Valencia.

LÓPEZ GANDÍA, J. (2006): Las sociedades laborales y la aplicación del derecho del trabajo, Tirant Io Blanch, Colección Laboral, Valencia.

MARTÍN LÓPEZ, S. (2010): "La necesidad de reactivación del crecimiento de las sociedades laborales y la reforma de su legislación: análisis económico-financiero de sus principales implicaciones", REVESCO, Revista de Estudios Cooperativos, 102, 109-144.

MARTÍN LÓPEZ, S., GARCÍA-GUTIÉRREZ FERNÁNDEZ, C. \& LEJARRIAGA PÉREZ DE LAS VACAS, G. (2010): "Las dificultades de financiación de las empresas de participación ante la crisis económica: la creación de una entidad financiera de crédito como alternativa", REVESCO, Revista de Estudios Cooperativos, 100, 11.

MARTÍN LÓPEZ, S., LEJARRIAGA PÉREZ DE LAS VACAS, G. \& ITURRIOZ DEL CAMPO, J. (2005): "Casuística de acceso a la actualización de la prestación por desempleo: bases para un modelo de decisión", CIRIEC-España, Revista de Economía Pública, Social y Cooperativa, 52, 307-333. 
MERCADER UGUINA, J.R. \& GIMENO DÍAZ DE ATAURI, P. (2010): "La capitalización de la prestación por desempleo", Revista del Ministerio de Trabajo y Asuntos Sociales, 89, 157-193.

MINISTERIO DE EMPLEO Y SEGURIDAD SOCIAL (2016): Anuario de Estadística de 2015. En: http://www.empleo.gob.es/es/estadisticas/anuarios/2015/index.htm.

MORENO PÉREZ, J.L. (1997): El sistema de protección por desempleo en España, Tirant Lo Blanch, Valencia.

PLAZA-ANGULO, J.J. (2011): Las sociedades laborales andaluzas: factores de supervivencia, Málaga, UMA-Tecnolex.

PLAZA-ANGULO, J.J. \& RICO BUENO, N. (2013): "La importancia del pago único de la prestación por desempleo en las sociedades laborales andaluzas y la reforma legislativa de 2013: otra oportunidad perdida", VII Coloquio Ibérico Internacional de Cooperativismo y Economía Social: Empresas sociales, economía social y crisis del Estado de Bienestar en la Unión Europea, Sevilla, organizado por CIRIEC-España, CIRIEC-Portugal y CEPES-Andalucía.

RICO BUENO, N. (2013): "Modificaciones en materia de desempleo introducidas en las reformas de 2012". En: Castellano Burguillo, E. \& Feria Basilio, I. (Coord.), Estudios en torno a la Reforma Laboral de 2012, Punto Rojo Libros, 315-338.

SÁNCHEZ PACHÓN, L.A. \& CHINARRO PÉREZ, E. (2015): "Las entidades de economía social como protagonistas de un nuevo modelo de emprendimiento y medidas legales de apoyo al emprendimiento", CIRIEC-Espana, Revista de Economía Pública, Social y Cooperativa, 84, 35-62.

SANCHIS PALACIO, J.R., CAMPOS CLIMENT, V. \& MOHEDANO SUANES, A. (2015): "Factores clave en la creación y desarrollo de cooperativas. Estudio empírico aplicado a la Comunidad Valenciana", REVESCO, Revista de Estudios Cooperativos, 119, 183.

SERRANO GARCÍA, J.M. (2014): "Los aspectos laborales de la ley de emprendedores: promovedora del empleo 'sin derechos"', Revista jurídica de Castilla-La Mancha, 55, 65-102.

\section{Referencias Legislativas}

Constitución Española de 1978, de 29 de diciembre de 1978.

Real Decreto 1044/85, de 19 de junio, por el que se regula el abono de la prestación por desempleo en su modalidad de pago único por el valor actual de su importe como medida de fomento del empleo.

Ley 5/2011, de 29 de marzo, de Economía Social.

Ley 31/2015, de 9 de septiembre, por la que se modifica y actualiza la normativa en materia de autoempleo y se adoptan medidas de fomento y promoción del trabajo autónomo y de la Economía Social.

Real Decreto Legislativo 8/2015, de 30 de octubre, por el que se aprueba el texto refundido de la Ley General de la Seguridad Social. 


\section{Anexo}

\section{Cuestionario}

Nombre de la empresa:

Año de fundación:

Actividad:

Capital social:

1. ¿Cuántos socios trabajadores son en su empresa?

2. ¿Cómo financiaron el inicio de la actividad empresarial?

a) El $100 \%$ con capital propio

b) Entre 51 y $75 \%$ con capital propio

c) Entre 26 y $50 \%$ con capital propio

d) Entre 0 y $25 \%$ con capital propio

3. ¿Cuántos de sus socios han capitalizado la prestación por desempleo para formar parte de la empresa?

4. ¿Qué cuantía han capitalizado para ingresar o constituir la empresa?

5. ¿El poder contar con el pago único ha sido determinante para constituir la empresa o integrarse en ella?

6. ¿Han obtenido algún otro tipo de ayuda o subvención pública para iniciar su actividad empresarial 
